\title{
Nietzsche: sobre alguns problemas morais da democracia moderna
}

\author{
Adriana Delbó*
}

\begin{abstract}
Resumo: Para compreender as análises da política por Nietzsche é necessário compreender sua análise da moral cristã. Limitadas concepções do que sejam "bom" e "mau" sustentam as demandas por proteção, paz, longevidade. Para ser avaliado como bom, o governo deve prometer o cuidado das condições da mera existência. Assim, Nietzsche avista a política de sua época conduzindo adiante homens debilitados. Por pensar a política como instrumento para elaboração de cultura, sua tarefa consistiria em fortalecer o homem e seus modos de organização do viver em comum. Neste sentido, a genealogia da moral e o projeto de transvaloração dos valores representam um desafio a todos que se propõem a pensar a política. Palavras chave: política - cultura - moralidade cristã - transvaloração dos valores
\end{abstract}

A despeito de a democracia ser um princípio político muito caro à nossa época, ela será aqui objeto de análise à luz do pensamento de Nietzsche e, por decorrência, as reflexões acerca desse assunto não terão utilidade para sua defesa, para proposta de aperfeiçoamento, nem para as maiores fundamentações e justificações. Nas considerações de Nietzsche a respeito da política destacam-se seus ataques à democracia moderna: ele discerne no movimento democrático uma herança cristã e, em vista disso, o avalia como expressão de uma moral alimentadora do animal de rebanho, e, portanto, do rebaixamento e amolecimento da humanidade; acusa os

\footnotetext{
* Professora da Universidade Federal de Goiás (UFG), Goiás, Brasil. E-mail: adrianadelbo@ gmail.com.
} 
Estados democráticos de fazer prevalecer a concepção do governo como instrumento da vontade popular; e, em vista disso, ser modelo exemplar para as relações instrumentais e comerciais formadas nas demais esferas sociais. Por fim, a democracia moderna é, para Nietzsche, o declínio do Estado.

Não obstante, ao contrário do desprezo pela política, comumente atribuído a Nietzsche, reconhecemos em seus escritos a relevância dada a ela, por compreendê-la como instrumento para a elaboração de cultura em vista da organização social favorável ao engrandecimento, fortalecimento e infindável autoelaboração humana. Embora seus posicionamentos acerca desta temática sejam bastante ácidos, eles revelam sua preocupação com a política no que concerne ao destino que ela traça para a humanidade; também esclarecem os critérios da sua análise da política: as perguntas pelo tipo de cultura gerada, o tipo de moral em que se ampara, o tipo homem que a sustenta e que por meio dela é fortalecido. A compreensão do papel da política no pensamento de Nietzsche requer atenção à relevância da sua genealogia da moral e da sua transvaloração dos valores.

A leitura fragmentada dos escritos de Nietzsche poderia nos levar a crer exatamente no que ele jamais defendeu. Poderíamos excluí-lo do âmbito filosofia política, afinal, ele mesmo, na obra Humano, demasiado humano menciona um distanciamento da política alegando que "é preciso permitir a alguns, mais do nunca, que se abstenham da política e se coloquem um pouco à parte" (MA I/HH I 438, KSA 2.286). Não obstante, na crítica de Nietzsche à modernidade destacam-se suas análises da política em sua preocupação maior com a cultura. Para ele, a origem da concepção de Estado como promotor da paz e do cuidado da vida é imensamente responsável pela decadência do homem em vista de sua possibilidade de elaboração de cultura. Já nos seus primeiros escritos a respeito da política, quando analisa a cultura grega, ele estabelece um entrelaçamento entre cultura e política por meio de paralelo entre as contribuições da política para criação de cultura na antiguidade, 
e as dificuldades decorrentes da política moderna para o alcance desta tarefa. No mesmo sentido, em $O$ nascimento da tragédia, Nietzsche anuncia uma misteriosa conexão entre arte e Estado gregoA principal percepção de Nietzsche da política, na era moderna, é que, com o declínio da autoridade religiosa, a decadência do estado tradicional e o desgaste da lei e dos costumes tradicionais, a relação entre indivíduo e a sociedade necessita de reconstrução e reavaliação. Essa percepção não é de modo algum exclusiva ou originalmente sua, mas revela, como uma das preocupações prevalecentes de Nietzsche, até que ponto seu típico retrato como filósofo apolítico é profundamente falho e inadequado

Em Além de bem e mal, destacam-se os contornos por meio dos quais Nietzsche pensa a política: um longo, poderoso, embora quase invisível, alcance da moral. Encontramos associado à política algo que na época moderna julga-se já estar afastado dela, mas que por Nietzsche é visto e avaliado como o grande mal da política moderna: a moral cristã. Enquanto o homem moderno julgava poder se orgulhar da conquista da política secularizada, livre de influências religiosas, Nietzsche reconhece na democracia moderna uma herança do movimento cristão (JGB/BM 202, KSA 5.124-6).

A filiação da democracia moderna ao movimento cristão já estava posta, ainda que não explicitamente, em Humano, demasiado humano II. No aforismo 472, Nietzsche já se reporta ao problema de a noção de hierarquia ser totalmente contaminada pelas avaliações morais quando "começa a prevalecer" a concepção de governo "ensinada nos Estados democráticos". O Estado, ao passar a ser compreendido e defendido como instrumento dos mais fracos, dos que precisam de proteção - e neste momento julgamos que Nietzsche se reporta às tentativas de fundamentação do Estado em vista da proteção à vida humana -, passa a ser visto "apenas" como "instrumento da vontade popular, não um 'alto' em comparação a um 'baixo', mas meramente uma função do único soberano, do povo" (MA I/ HH I 472, KSA 2.303). Por esse mesmo motivo, Nietzsche responsabiliza o Estado democrático por conduzir o Estado à morte: 
as sociedades privadas incorporam passo a passo os negócios do Estado: mesmo o resíduo mais tenaz do velho trabalho de governar (por exemplo, as atividades que se destinam a proteger as pessoas privadas uma das outras) termina a cargo de empreendedores privados. $\mathrm{O}$ desprezo, o declínio e a morte do Estado, a liberação da pessoa privada (guardo-me de dizer: do indivíduo), são consequência da noção democrática de Estado; nisso está sua missão (MA I/ HH I 472, KSA 2.305).

Contudo, em suas críticas aos valores que amparam a democracia moderna, Nietzsche evidencia um grave limite: o cuidado das condições de vida de uma época associado à falta de comprometimento com o cultivo e o fortalecimento do que se manifesta como potencialidades humanas a qualquer tempo. Na obra Humano, demasiado humano, Nietzsche defende que a dedicação ao Estado não deve ser tarefa de quem se mobiliza apenas com o imediato, com as demandas do seu próprio tempo, de sua própria vida e da vida de seus contemporâneos. Uma política restrita a essa relação com o presente seria decorrência do consentimento ao egoísmo, a despeito deste sentimento ser alvo de crítica por parte da moralidade reguladora desta mesma política. Ao recusar o presente como elo suficiente de ligação entre o homem e a política, Nietzsche defende que somente aquele que se preocupa com um futuro deve se ocupar com governo de um povo.

Quando um homem não tem filhos, não tem pleno direito de intervir na discussão sobre as necessidades de um Estado. É preciso ter arriscado, juntamente com os outros, aquilo que mais se ama: apenas isso vincula fortemente ao Estado; é preciso ter em vista a felicidade de seus pósteros, e por isso, antes de tudo, ter pósteros, a fim de participar justa e naturalmente nas instituições e em suas mudanças. O desenvolvimento de uma moral superior depende de que a pessoa tenha filhos; isso desfaz o seu egoísmo, ou, mais corretamente: isso amplia o seu egoísmo no tempo, e faz perseguir seriamente objetivos que vão além da duração da vida individual (MA I/HH I 455, KSA 2.295). 
A inquietação com o quanto a política se compromete com a organização da vida pública em função do cultivo das potencialidades humanas é o que, para Nietzsche, justifica o elo entre os homens e o Estado. A isso se deve seu rechaço às tarefas limitadas comumente requeridas à política: cuidado do presente, responsabilidade restrita com formas de organizações de poder, durabilidade da vida a qualquer preço, luta restrita pelas condições de existência. Ao demandar que se tenha um interesse muito além do amparo à existência dos que se fazem presentes, de tornar a vida segura, confortável e prazerosa, Nietzsche não deixa de admitir relevância à política; ele tão somente se recusa a estar entre aqueles que compreendem a política como cuidado da vida de uma coletividade, de um rebanho satisfeito. A dedicação ao Estado deve ser, portanto, preocupação de quem pensa mais do que em si mesmo e em seu tempo. $\mathrm{O}$ que deve vincular o homem ao Estado é um compromisso com o futuro, com a durabilidade de suas criações, com as possibilidades e condições para o que é humano para além da duração da própria vida.

É a partir da perspectiva da denúncia da fragilidade dos valores que amparam a política na modernidade que devemos interpretar o aforismo 470 de Humano, demasiado humano: o político é o lobo por trás da ovelha. O político precisa se travestir, de lãs que o proteja, tendo em vista os valores a que estão submetidos a política, o que é considerado "bom", o que é cobrado e aceito para bem avaliar os governantes. Nietzsche compara a necessidade inevitável que o político tem de uma presa à necessidade que um caçador tem pela mesma. Ironicamente, então, ele associa a situação de caça à única semelhança entre o político e o homem honesto: nesta circunstância ambos precisam buscar estratégias, ardis, embustes, para satisfazer uma necessidade básica. Mas enquanto o caçador devora o cordeiro que captura para saciar sua fome, o político, para conseguir governar, usa o cordeiro "para se esconder atrás de seu dorso lanoso" (MA I/ HH I 470, KSA 2.301). Isso não porque a desonestidade é inerente ao político, mas porque, na modernidade, somente com tais estratégias ele é aceito e bem avaliado. Não se trata de defender 
a impossibilidade de honestidade entre os políticos, mas de diagnosticar as "determinadas circunstâncias" nas quais o político tem a mesma necessidade de um homem honesto: quando precisa conseguir o que lhe é mais básico. No caso de precisar governar, a partir da concepção de soberania popular, ele deve atender à vontade do povo. Ao governo resta tentar lidar com os inúmeros, diversos e até inconciliáveis interesses daqueles que julgam permitir o poder - o que requer, portanto, vestir-se com a pele de um cordeiro. Somente as características do cordeiro são consideradas boas quando o único amparo da moralidade é a moralidade cristã.

À espreita da ideia de que todos os que sofrem são os merecedores atenção, de que o sofrimento é o alvo a ser atacado e combatido na vida política, de que a boa sociedade é aquela que cumpre a tarefa da redimir as dores e de gerar o conforto, pairam os liames traçados por Nietzsche entre sociedade moderna e rebanho. A sociedade que pudesse ser avaliada como a mais justa pela igualdade promovida e pela dedicação à política movida por interesses impessoais, aproxima-se da imagem de um amontoado de indivíduos que se unem a fim de se protegerem, se auxiliarem, se cuidarem, enfim, ganharem forças e se direcionarem impetuosamente contra tudo o que põe em risco a segurança, o bem estar e o comodismo, tal como é perfeitamente capaz de fazer um rebanho. É esta a imagem que a Nietzsche repugna e que o faz denunciar os interesses existentes na política moderna: vontade de proteção, de cuidado, de vida cômoda, interesses típicos de seres debilitados que só podem pedir, reivindicar, exigir - seres, portanto, vitimados. E é contra essa tarefa que ele se coloca quando assume um distanciamento da política de sua época, mas não deixa de avaliá-la tornado evidente a moral que a degenera.

É por reconhecer que o envolvimento com a política na modernidade está amparado fundamentalmente na vontade de proteção da vida e na necessidade de fuga do sofrimento e, portanto, que a atividade política deve ser a busca de estratégias para o alcance de tais metas, que para Nietzsche ela se torna cada vez mais sustentáculo 
da estrita condição animal de rebanho. Como construto humano para domesticação, a moral alcança um nível perigoso no que diz respeito às possibilidades humanas de elaboração de si para além da organização social.

Quando se podem diferenciar as várias formas que o homem tem em si, então, as formas mais elevadas são as correspondentes a seu "ser-não-determinado", ou seja, formas que deixam em aberto muitas possibilidades. Ao fanatismo que domina "em um único ponto de vista e sentimento", Nietzsche contrapõe a liberdade, em condições de construir algo em meio a várias possibilidades. Nietzsche defende essa noção do suportar as muitas possibilidades daquela moralidade que, em virtude da sua uniformidade, rouba do homem justamente suas possibilidades, reconduzindo-o a um perfeito adestramento; defende esse suportar contra uma moralidade cuja força 'desenvolve apenas o animal de rebanho no homem...

Nietzsche delimita o par moral e política da limitação. Moral limitadora de seus próprios criadores, política regularizadora dos limites humanos; em vista dos entrelaçamentos entre política e a moral, Nietzsche interpreta os movimentos políticos de sua época como os condutores de rebanhos, reivindicadores e zeladores de políticas para preservação da vida, limitados à exigência de "preservação da comunidade" (JGB/BM 201, KSA 5.121). É nesse contexto que precisamos compreender sua defesa de que o movimento democrático "não é simplesmente um modo de degradação da organização política, mas, além disso, um modo de degradação e apequenamento do homem, sua mediocrização e rebaixamento de valor" (JGB/BM 203, KSA 5.126). E é considerando tudo isso que se deve compreender o distanciamento que Nietzsche deseja da política anunciado já em Humano demasiado humano, pois,

quando em toda política o importante é tornar suportável a vida para a maioria das pessoas, que essa maioria conclua então o que entende 
por uma vida suportável; se confiam também que o seu intelecto encontre os meios adequados para alcançar este fim, para que duvidar disso? Eles querem ser os forjadores da própria felicidade ou infelicidade; se este sentimento de autodeterminação, o orgulho pelas cinco ou seis noções que a sua mente comporta e demonstra, lhes torna realmente a vida agradável, a ponto de suportarem com gosto as fatais consequências de sua estreiteza,: então não há muito o que objetar, desde que a estreiteza não chegue ao cúmulo de exigir que tudo deve se tornar política nesse sentido e que todos devem viver e agir conforme esse critério (MA I/HH I 438, KSA 2.285-6).

O exame dos sentimentos, das vontades, dos interesses e impulsos, opera constantemente na análise nietzscheana da política. Assim, as condições de manutenção da existência, não são seus critérios de avaliação da eficiência ou ineficiência de um Estado. Se a instituição pública de poder tem por tarefa o atendimento das carências e debilidades humanas, ela conduz adiante a fraqueza nos homens e, deste modo, compromete o futuro dos homens e da própria política, por fazer desta um mero dispensário da humanidade. Ao adotar princípios morais restritos e envenenadores do homem, a política tem o seu próprio funcionamento e objetivo reduzidos. Daí a aversão de Nietzsche pela política moderna enquanto propiciadora de experiências que somente atendem ao ímpeto de saciedade e de proteção. Se as exigências para a política se restringem à garantia de seguridade e paz, se tão somente a igualdade e o desinteresse por si são valores aceitos, todos os demais ímpetos humanos, rechaçados pela limitada moralidade moderna, carecem de condições de propagação. Neste sentido, o Estado torna-se instrumento para a diminuição e adoecimento do homem.

Em vista disso, Nietzsche defende, citando Maquiavel (O príncipe), que: "a forma dos governos é de importância bem pequena, apesar de que, gente semiculta pense de outra forma. A grande meta da arte do Estado deveria ser a duração, que contrabalança todo o restante, e é muito mais valiosa do que a liberdade" (MA I/ 
HH I 224, KSA 2.189). Ocupar-se com o que terá durabilidade, o que é levado adiante no processo social conduzido pelo Estado, tem maior relevância valorativa para Nietzsche do que o cuidado exclusivo com o quanto de satisfação o Estado promove. Pensar a política como cultivo do homem, requer preocupar-se com o tipo homem conduzido adiante pelas mãos do Estado - o homem pleno ou o degenerado. E o cultivo do que é humano não pode impor limites que degeneram o homem, muito menos denominar tal limitação como "bom" e "justo".

Para Nietzsche, nenhuma das correntes políticas de sua época conseguiu escapar dessa unanimidade da moral de rebanho que ele vê subjazer a todas as diferentes formas de se pensar e fazer política. Democratas, socialistas e anarquistas são "unânimes na inimizade radical e instintiva contra outra forma de sociedade que não a do rebanho autônomo"(JGB/BM 202, KSA 5.125). A recusa à ideia de "senhor" e de toda pretensão especial, de todos os direitos e privilégios particulares (que se quer leva à percepção de que na ausência total de desigualdade está ausente todo o significado e necessidade do "direito", "pois quando todos são iguais, ninguém precisa mais de "direitos"'), a desconfiança quanto à justiça punitiva, como se ela fosse sempre violência contra o mais fraco, a ideia de que a injustiça resulta sempre de toda sociedade anterior e, por fim, a crença de que o sofrimento pode ser eliminado da vida, inclusive por meio de estratégias políticas, são algumas das pretensões coincidentes entre todas as correntes políticas que Nietzsche reconhece em sua época. Todos querem a mesma coisa, lutam pelo mesmo ideal, e brigam entre si apenas no que diz respeito ao modo de alcançar o que querem. A isto Nietzsche denomina "moral da compaixão partilhada", adotada como a moral em si, que paira sorridente, mas inibidoramente, sobre toda "crença na comunidade redentora, isto é, no rebanho em "si"' (JGB/BM 202, KSA 5.125).

Assim, Nietzsche não rechaça a política, nem nega sua relevância. O problema denunciado por ele é de outra ordem: quando os ímpetos de proteção, de cuidado, de vontade de justiça e igualdade, 
são os únicos condutores da vida política, ela molda a vida humana assemelhando-a à vida de animais de rebanho, unidos para se protegerem, ainda que entre os humanos isso se dê de modo mais sofisticado. Estimulada pela vontade de proteção, cuidado, compaixão pelos que sofrem, a política ajuda a cultivar um ideal humano que "animaliza o homem, tornando-o bicho anão com direitos e deveres iguais" (JGB/BM 203, KSA 5.126). Nietzsche não põe em dúvida a possibilidade de que a sociedade livre, tal como desejavam os socialistas de sua época, fosse alcançada: o problema é a tarefa demasiadamente degenerativa a que a política se coloca diante dos esforços para tal conquista.

Os objetivos postos para a política e ditos impessoais são para Nietzsche um perigo para a sociedade. Entre aqueles que "querem alcançar algo para si", "aqueles que querem alcançar algo para seus filhos e netos" e o que querem os "revolucionários movidos por interesse impessoal” (MA 1/ HH 1 454, KSA 2.295), esses últimos são para Nietzsche os verdadeiramente perigosos. Isto porque, por se julgarem moralmente superiores a todos os outros, por se considerarem pessoalmente desinteressados, eles se opõem a tudo o que não coincidir com seus ditos interesses impessoais. Desse modo, todos os defensores da ordem vigente, independente do que fizerem e defenderem, serão seus inimigos, porque bom é ser desinteressado. De tal forma que a dedicação ideal à sociedade, a tudo aquilo em torno do que se luta, é impulsionada pela crença e a pela boa consciência do desinteresse.

A superioridade daqueles que alegam nada querer para si representa um risco para a política e para o futuro da humanidade: a atividade humana, que visa exatamente lidar com interesses, com os tipos de vida que querem os homens, com o que querem que seja fixado na vida pública, fica contaminada pela exigência de desinteresse e fica desprovida de determinações vigorosas que mobilizem o futuro - com isso, a atividade política se torna reativa. Assim, reconhecer e assumir os interesses que movimentam a dedicação ao Estado é, nesta perspectiva, melhor do que a defesa do altruísmo. 
Para a vida política, ante a condenação moral dos interesses, é preferível o reconhecimento de quais são os interesses em jogo - se eles fortalecem ou debilitam o homem.

O desapreço de Nietzsche pelo suposto predomínio dos interesses impessoais na política nada tem a ver, portanto, com a defesa de que quaisquer interesses sejam válidos. O problema daqueles que "querem alcançar algo para si" é que eles podem ser alimentados e, por isso, tornarem-se "contentes", "satisfeitos" e "saciados" (abspeisen); e, "para tanto a sociedade dominante é suficientemente rica e esperta" (MA I/HH I, KSA 2.295). Desta esperteza, nasce, por exemplo, a concepção de governo como instrumento da vontade popular.

$\mathrm{Na}$ avaliação nietzscheana dos valores, recusar-se também seria uma forma de egoísmo. Conforme o aforismo 516 de Aurora, "fugir do ego", odiá-lo, "viver no outro", tudo isso que é demandado para ser considerado "altruista" e, portanto, "bom", é um meio de se abster de si e de transferir a todos seus próprios demônios. Mas para não deixar seu demônio entrar no próximo, é necessário conceber a possibilidade de se pensar de outro modo.

Nós concordamos que em nosso tempo, benevolência e beneficência fazem o homem bom; façamos apenas um acréscimo: 'supomos que ele antes seja benevolente e beneficente consigo mesmo!' Pois sem isso se ele foge de si, se ele se odeia, se ele se prejudica - certamente ele não seria um bom homem. Então, ele somente salva-se de si mesmo nos outros: esses outros cuidem para não ficarem mal, por mais bem que aparentemente ele lhes queira! Mas exatamente isso: fugir do ego e viver no outro, para o outro - o que foi até agora considerado 'altruísta' e ‘bom’ (M/A 516, KSA 3.299).

Portanto, Nietzsche avalia que o cuidado e o amor de si não são prejudiciais à política. Antes o contrário, são modos de valorizar-se, salvar-se dos próprios limites, prejuízos, demônios da vida privada e pública. 
O altruísmo, enquanto princípio compreendido como necessariamente bom e exigido na vida política, é, do ponto de vista nietzscheano, uma exigência que cega a avaliação das atividades realizadas pelo governo. Apesar de ser constituída por homens, que não podem abandonar sua condição humana, exige-se e espera-se que a arte de governar seja feita com total isenção. Em vista disso, Nietzsche realça o perigo do altruísmo, afinal "a deslealdade e a rispidez que constituem a obra do estadista" podem não ser sequer percebidas, porque "o brilho do altruísmo ofusca os olhos do espectador" (MA I/HH I 445, KSA 2.289). Se a nobreza de caráter do estadista depende inteiramente de sua ação totalmente isenta de interesses que também podem ser seus, resta somente ser altruísta, porque o altruísmo é bom "em si". Basta o estadista eleger para sua ação um princípio aceito unanimemente para mesmo a obra executada apenas em benefício de si mesmo ser compreendida como dedicação a algo superior. Não importa o que se quer da vida em sociedade, as limitações do que é demandado da política, quais as decorrências das decisões e ações políticas, que tipo de sociedade está sendo conduzida adiante por meio dela, desde que sejam destacadas as ações em benefícios de outros, que signifiquem a recusa de si, a liberação do que lhe é próprio, enfim, as boas ações, desinteressadas, livres do egoísmo. Nietzsche desvela assim a decadência e o apequenamento da política em um contexto no qual cabe ao estadista meramente descobrir e adotar um valor aceito por seu povo e, em vista disso, alegar estar a serviço do soberano. A condução da política pelas rédeas do princípio moral altruísta exige do estadista a necessidade de negar seus interesses, atribuí-los a outros, mais aceitos, para que ele possa governar e ter sua obra bem avaliada. Compreendida como autorização do poder em vista de benefícios gerados, ao governo resta descobrir o que querem dele, e ao povo exigir o que a ele falta. Pela relação utilitária entre governo e governados, a política se reduz a ofertas e cobranças.

$\mathrm{O}$ motivo para o combate nietzschiano contra a política em $\mathrm{Au}$ rora continua sendo o mesmo já presente no escrito de juventude, 
"O Estado grego": a estruturação do Estado moderno em vista da oferta de condições para a manutenção da mera vida. E independentemente do conforto e da durabilidade que possa ser alcançado, nada disso é suficiente para que o homem transponha a condição de escravidão exigida pela própria manutenção da existência. A saciedade alcançada tem efeito passageiro e sempre lança os homens novamente no mesmo ciclo de necessidades e carências, cujas satisfações os devolvem imediatamente à condição escrava. A política mantenedora e protetora da vida não é libertária. O homem orgulhoso, crente na sua dignidade e cego para sua própria escravidão, é desde os primeiros escritos de Nietzsche um objeto da sua análise da política. Neste mesmo sentido, em Aurora, Nietzsche descreve a cena que antevê para o século XX: o estabelecimento de valores por parte dos mercadores atingindo "todo o caráter de toda cultura, pensado com máxima vastidão e sutileza, impondo-se a toda vontade e possibilidade: é disso que vocês, homens do próximo século, estarão orgulhosos" (M/A 175, KSA 3.156).

A recusa de Nietzsche a esta política democrática deve-se à mobilização dela rumo a preocupações próprias e imediatas de uma época e de um tipo homem travestidas de preocupações comuns. Ele se refere às construções resultantes desses limitados vínculos como cultura de mercadores - "a cultura de uma sociedade em que o comércio é a alma, assim como o combate individual o era para os antigos gregos, e a guerra, a vitória e o direito o eram para os romanos" (M/A 175, KSA 3.155). E as decorrências deste pensamento básico, que ele alega ver surgir em sua época, colocam em risco todas as outras instâncias da vida, porque "esse modo de estima" o mercador "emprega, instintivamente e ininterruptamente para tudo, inclusive para as realizações da arte e da ciência, dos pensadores, doutores, artistas, estadistas, de povos e partidos, de épocas inteiras: em relação a tudo o que é produzido, para estabelecer para si o valor de uma coisa, sua pergunta é pela oferta e pela demanda" (M/A 175, KSA 3.155-6). 
É porque a tarefa de instituir os valores a cada coisa ocorre a partir da perspectiva típica de um mercador e atinge as funções do estadista, dos povos e dos partidos, que Nietzsche mantém seus inúmeros ataques à política democrática. As preocupações do mercador são, para ele, nocivas para a política e para todas as outras elaborações da vida de um povo. E é por ver toda a cultura envolta por estimativas de valor reduzidas à oferta e à demanda, que os vínculos entre política e cultura na modernidade, são para, ele perniciosos.

Longe de poder ser sustentada por um fio condutor da utilidade, saciedade e bem estar, Nietzsche defende que uma genuína cultura manifesta-se pela "unidade do estilo artístico em todas as expressões da vida de um povo" (HL/Co. Ext. II, KSA 1.274). Em sua época, no entanto, a única unidade identificada por ele em tudo o que fora criado e valorado foi o cálculo de valores conforme a oferta e a demanda - exatamente o oposto de um "estilo artístico", de uma vontade de arte, de criações belas, criações humanas que não geram saciedade e estão liberadas da utilidade.

Aos olhos de Nietzsche, a decadência da política moderna deve-se ao seu funcionamento limitado por preocupações com "o que" e "quantos possuem", e à restrita valorização concedida à política quando condicionada aos esforços por atender necessidades urgentes e momentâneas. Ela é o palco do mercador, que por não ter necessidades próprias, se orienta "conforme a necessidade dos consumidores", e, portanto, pelas perguntas: "quem e quantos consomem isso?" (M/A 175, KSA 3.155). Portanto, é esse tipo homem, ora carente, ora saciado, que é conduzido adiante pelas mãos da política; é essa a herança que a política moderna lega às épocas vindouras. É o curto movimento possível entre necessidades e saciedades que impele a modernidade europeia. $\mathrm{O}$ funcionamento eficiente da vida política gera no máximo indivíduos satisfeitos. $\mathrm{E}$ a ausência de vontades, de desejos por aquilo que não gera saciedade, de vontades maiores - tal como a vontade artística -, reduz a possibilidade de elaboração de cultura, de criação, de imitação da 
atividade de natureza, algo que só pode acontecer entre os homens. Incapacitado de realizar a sua atividade suprema, o homem, portanto, torna-se debilitado.

Contudo, é pela defesa cega da igualdade, que a aceitação unânime da democracia moderna é possível: sem se perguntar pelo que tal igualdade significa, o que ela alcança e promove, a que ela nivela o humano, a política democrática moderna segue exultante, escondendo os corpos débeis por ela produzidos.

Aos olhos de Nietzsche, os homens modernos não reconhecem o ridículo de suas reivindicações mais destacadas, mais desgastantes, mais inférteis. Neste sentido, em Humano, demasiado humano, ele pergunta: "Se alguém mostra tiras de carne fresca ensanguentada diante do nariz de uma fera e depois as retira, até que finalmente ela ruge: vocês pensam que esse rugido significa justiça?" (MA I/HH I 451, KSA 2.293). Ridiculariza assim o que julga ser a opção da política democrática moderna ao adotar como tarefa principal o manuseio de um pêndulo hipnotizador. Ele julga que é exatamente pela unanimidade cega com que se defende o princípio da justiça que ela se torna chamariz dos partidos, a moeda de troca e de compra que mantém a vida política na modernidade:

Representantes mais nobres (apesar de não muito perspicazes) da classe dominante podem muito bem prometer a si mesmos: 'Nós vamos tratar os homens como iguais, vamos lhes dar direitos iguais'. Quanto a isso, um modo de pensar socialista baseado na justiça é possível; mas, como já dito, somente de dentro da classe dominante, que nesta armadilha, exerce a justiça com sacrifícios e renúncias. Por outro lado, reclamar igualdade de direitos, como fazem os socialistas da casta subjugada, não é jamais produto da justiça, senão da cobiça (MA I/HH I 451, KSA 2.293).

Nietzsche questiona não a busca por justiça, mas o fato de a política moderna ter assumido a bandeira da justiça sem ser capaz de reconhecer o que significou para seu próprio funcionamento tal 
aceitação irrestrita e inquestionável. Mais uma vez nota-se que denuncia o quanto a política moderna se traduz na adoção de restritos princípios morais e a redução de seu funcionamento somente à órbita em torno deles.

Além de não ser possível coadunar o pensamento de Nietzsche com as inconsequentes e incoerentes aproximações da política nazista, suas investidas contra a supremacia dos ideais de igualdade e direitos na política também não traduzem sua recusa a tais princípios. Contudo, enquanto fundamentos inquestionáveis, ponto de partida e de chegada nos modos de ver, defender e fazer a política, Nietzsche os critica por diagnosticar a diminuição das potencialidades humanas e o definhamento da própria atividade política. Ao constatar as consequências danosas da redução da política a gritos por igualdade e direitos, Nietzsche não propõe que eles sejam negados em nome da desigualdade e da força.

A força impiedosa da moral de rebanho manifesta no modo como a hierarquia, a desigualdade e a autoridade são acima de tudo rechaçadas e impensadas; a naturalidade com que algumas ideias são aceitas e defendidas sem restrição e crítica - tais como a de que todos os que sofrem são os que merecem atenção, de que o sofrimento é o alvo a ser atacado e combatido na vida política, de que a boa sociedade é aquela que cumpre a tarefa da redenção das dores e de geração de conforto - alteram-se à luz da análise nietzscheana. Se conseguíssemos, por alguns instantes, visualizar uma sociedade, considerada a mais justa, como um amontoado de indivíduos que se unem a fim de se protegerem, se auxiliarem, se cuidarem, se unirem para ganhar forças e se direcionar impetuosamente contra tudo o que põe em risco a segurança, o bem estar e o comodismo, tal como é perfeitamente capaz de fazer um rebanho, visualizaríamos, então, a imagem que a Nietzsche enoja e que o faz denunciar os interesses, supostamente justos e desinteressados, da política moderna: vontade de proteção, de cuidado, de vida cômoda; interesses típicos de seres debilitados que só podem pedir, 
choramingar, reivindicar, exigir, reclamar. Seres, portanto, fragilizados. E é contra essa tarefa, defendida e alcançada pela política democrática, que Nietzsche se coloca.

Ao assinalar os danos de uma política reduzida a gritos por saciedades e garantias, Nietzsche não propõe a substituição destas reivindicações pela promoção da desigualdade e da força. Uma vez percebido que o foco de análise nietzscheana da política é o seu reducionismo à moral cristã e os riscos para o cultivo de homens mais completos e mais fortalecidos, é possível compreender sua relevância para a reflexão filosófica a respeito da política.

Uma transvaloração dos valores é a proposta da filosofia de Nietzsche, que se mostra também uma tarefa no âmbito da política. Somente a partir dela seriam possíveis transformações na política amparada em valores restritos e perniciosos à elaboração infindável da humanidade. Nas relações estabelecidas por Nietzsche entre vida e política, a decadência da segunda ocorre em função da reduzida compreensão da primeira. Por isso, Nietzsche já poderia ser incluído entre os primeiros dos pensadores dos problemas relacionados ao que vem sendo chamado, ao menos desde Foucault, de biopolíticaAlém disso, contamina a atividade política, propriamente humana, que deveria estar destinada a decisões e elaborações de modos de vida, de cultivo do homem para além da busca de sobrevivência e de comodidade. Longe de lidar com ímpetos de força, poder, mando, obediência, promovendo um espaço onde tudo o que é humano é extravasado e, em vista disso, regulado, como uma espécie de catarse, a política passou a ter seus atributos específicos camuflados. É uma moralidade limitada que a autoriza e, portanto, que a debilita.

\footnotetext{
Abstract: To understand the Nietzsche's analysis of politics is necessary to understand his analysis of Christian morality. Limited conceptions of what constitutes "good" and "bad" sustain the demands for protection, peace, longevity. To be rated as good, government must promise the care of the conditions of mere existence. Thus, Nietzsche sees the politics of
} 
his time conducting forward debilitated men. Because conceives politics as a means for development of culture, its task would be to strengthen the man and his ways of organize the living together. In this sense, the genealogy of morals and the project of transvaluation of values represents a challenge to all who intend to think of politics.

Keywords: politics - culture - Christian morality - transvaluation of values

\section{referências bibliográficas}

ANSELL-PEARSON, K. Nietzsche como pensador politico: uma introdução. Trad. Mauro Gama e Claúdia Martinelli Gama, Rio de Janeiro: Zahar, 1997.

DELBÓ, A. Misteriosa conexão entre arte e estado: a reflexão sobre a cultura no jovem Nietzsche. Campinas: UNICAMP, 2006 (Tese de doutorado).

CRAGNOLINI, M. (org.). Estrañas comunidades: La impronta nietzschiana en el debate contemporáneo. Buenos Aires: La Cebra, 2009.

GENTILI, C. Nietzsche. Trad. Beatriz Rabadán e José Luis Serrano. Madrid: Biblioteca Nueva, 2004.

LEMM, V. Nietzsche's Animal Philosophy: Culture, Politics, and the Animality of the Human Being. New York: Fordham University Press, 2009.

NIETZSCHE, F. Kritische Studienausgabe [KSA] (volume 1, 2, 3). Editado por Giorgio Colli e Mazzino Montinari. München: DTV; De Gruyter, 1999. . Além do bem e do mal. Prelúdio para uma filosofia do futuro. Trad. Paulo César de Souza. São Paulo: Companhia das Letras, 1992. . Aurora. Trad. Paulo César de Souza. São Paulo: Companhia das Letras, 2004. . Humano Demasiado Humano I. Trad. Paulo César de Souza. São Paulo: Companhia das Letras, 2000.

. Obras incompletas. Trad. Rubens Rodrigues Torres Filho. São Paulo: Nova Cultural, 1987 (Col. “Os Pensadores"), 2v.

. Segunda consideração intempestiva - Da utilidade e desvantagem da história para a vida. Trad. Marco Antônio Casanova. Rio de Janeiro: Relume Dumará, 2003.

TONGEREN, P. v. A moral da crítica de Nietzsche à moral: estudo sobre "Para além de bem e mal". Trad. Jorge Luiz Viesenteiner. Curitiba: Champagnat, 2012.

Artigo recebido em 04/11/2012.

Artigo aceito para publicação em 15/01/2013.

166 | cadernos Nietzsche 32, 2013 